\title{
Is the sleep apnoea/hypopnoea syndrome inherited?
}

Neil J Douglas, Marion Luke, Rajat Mathur

\begin{abstract}
Background-The aetiology of the sleep apnoea/hypopnoea syndrome (SAHS) is unclear in many patients. Snoring, a prerequisite for SAHS, runs in families. A study was carried out to determine whether there is an increased frequency of irregular breathing during sleep in relatives of patients with SAHS.

Methods-A prospective study was performed of first degree relatives of 20 consecutive non-obese (BMI $<30 \quad \mathrm{~kg} / \mathrm{m}^{2}$ ) patients with SAHS. Questionnaires on SAHS symptoms were sent to all first order relatives and those living within 150 miles of Edinburgh were invited for overnight monitoring of their breathing, sleep, and oxygenation patterns in the sleep laboratory.

Results-Ten of the 40 relatives had more than 15 apnoeas + hypopnoeas/ hour of sleep, and eight had more than five $4 \%$ desaturations/hour. These frequencies of irregular breathing and desaturation are significantly higher than in the British population. Cephalometric studies showed no skeletal abnormality but an increased uvular width was found in the affected relatives.

Conclusions-There is an increased frequency of abnormal breathing during sleep in relatives of non-obese patients with SAHS.
\end{abstract}

(Thorax 1993;48:719-721)

The aetiology of the sleep apnoea/hypopnoea syndrome (SAHS) ${ }^{12}$ in many patients is unclear. Snoring is a prerequisite for SAHS and is known to run in families. SAHS has been reported to run in two families ${ }^{34}$ but this may have resulted from an association with obesity. We have therefore performed a pilot study to investigate the hypothesis that SAHS may be inherited. To avoid studying the inheritance of obesity we have used only index cases who were non-obese.

\section{Methods}

Twenty consecutive new patients with SAHS (more than 15 apnoeas + hypopnoeas $(\mathrm{A}+\mathrm{H}$ ) per hour of sleep) with body mass index $<30$ $\mathrm{kg} / \mathrm{m}^{2}$ without evidence of gross retrognathia, hypothyroidism, or acromegaly took part in the study. These patients had a mean $\mathrm{A}+\mathrm{H}$ frequency of $42 /$ hour (range 17-76/hour), a mean body mass index of $27 \mathrm{~kg} / \mathrm{m}^{2}$ (range $24-29.5 \mathrm{~kg} / \mathrm{m}^{2}$ ), and a collar size of $41.1 \mathrm{~cm}$ (range $39 \cdot 4-44 \cdot 4 \mathrm{~cm}$ ). Each was asked to give details of all first degree relatives aged 18-75 years who were then sent a questionnaire relating to SAHS symptoms. All relatives who lived within 150 miles of Edinburgh were invited for a one night sleep study during which airflow at the mouth and nostrils was recorded by thermocouples, thoracoabdominal movement by induction stethogram, ear oxygen saturation by an Ohmeda Biox 3700 oximeter, and an electroencephalogram, electro-oculogram, and electromyogram were taken. Both sleep ${ }^{56}$ and breathing pattern ${ }^{6}$ were scored by standard criteria. All relatives attending for sleep studies had lateral cephalometry performed ${ }^{7}$ from which standard bony and airway dimensions were measured.

Differences between groups were assessed by the unpaired Student's $t$ test or $\chi^{2}$ test as appropriate. Correlations were performed with SPSS-PC.

Results

Three of the 20 patients had no eligible first degree relatives. We thus tried to recruit all eligible relatives of 17 patients (15 men; mean (SD) BMI $27 \cdot 4(1 \cdot 6) \mathrm{kg} / \mathrm{m}^{2}$ ). They had 76 first degree relatives but 14 lived more than 150 miles from Edinburgh. Six of the eligible 62 relatives stated they were too ill to attend for sleep studies and 16 refused. Forty relatives (19 men) therefore had overnight sleep studies. Nine of the 22 relatives who were unable to participate came from one family.

Twenty one (12 men) of the 36 relatives who did not have sleep studies replied to the questionnaire. These had a significantly higher rate of loud snoring (15 of 21) than the attenders (13 of 40 ), but were no different in terms of witnessed apnoeas, daytime sleepiness, or other SAHS symptoms.

\section{SLEEP STUDIES}

Ten (nine men) of the 40 relatives had more than $15 \mathrm{~A}+\mathrm{H} /$ hour of sleep (table). These "affected" relatives were older but were not more obese than the others. The affected 
Characteristics of relatives with $>15 A+$ H/hour of sleep or $<15 A+H /$ hour of sleep

\begin{tabular}{|c|c|c|}
\hline & $>15 A+$ H/hour & $<15 A+$ H/hour \\
\hline $\mathrm{n}$ & 10 & 30 \\
\hline Sex & $9 \mathrm{M}, 1 \mathrm{~F}$ & $10 \mathrm{M}, 20 \mathrm{~F}^{\star}$ \\
\hline Mean (SD) age (y) & $44(4)$ & $34(2) \dagger$ \\
\hline Mean (SD) BMI $\left(\mathrm{kg} / \mathrm{m}^{2}\right)$ & $27(1)$ & $25(1)$ \\
\hline Arousals/hour & $17(11-23)$ & $9(7-11)^{\star}$ \\
\hline Lowest $\mathrm{SaO}_{2}(\%)$ & $81(77-85)$ & $87(86-88) \dagger$ \\
\hline TST (min) & $328(303-353)$ & $345(327-363)$ \\
\hline SOL (min) & $18(10-26)$ & $25(16-34)$ \\
\hline SEI $(\%)$ & $79(72-86)$ & $85(80-90)$ \\
\hline
\end{tabular}

$\mathrm{A}+\mathrm{H}$-apnoeas + hypopnoeas; $\mathrm{BMI}$-body mass index; lowest $\mathrm{SaO}_{2}$-lowest oxygen saturation overnight; TST-total sleep time; SOL-sleep onset latency; SEI-sleep efficiency index; ${ }^{\star} \mathrm{p}<0.01 v$ relatives with $>15 \mathrm{~A}+\mathrm{H}$ /hour. $\mathrm{tp}<0.05 v$ relatives with $>15 \mathrm{~A}+\mathrm{H} /$ hour. Values in parentheses are $95 \%$ confidence limits unless stated otherwise.

relatives had more frequent arousals from sleep and lower minimal oxygen saturations than the 30 unaffected relatives. Eight of the 40 relatives had more than five $4 \%$ desaturations/hour. Factors significantly correlated with abnormal breathing during sleep were sex, body mass index $(\mathrm{p}<0.001)$, and age $(\mathrm{p}<0.05)$, but not collar size.

\section{QUESTIONNAIRES}

Eight of the 10 affected relatives were described as loud snorers compared with five of the 30 unaffected $(p<0.01)$. Similarly, witnessed apnoeas were more common in affected relatives $(5 / 8,0 / 25,(p<0.01))$, but there was no increase in daytime sleepiness $(2 / 10,10 / 30)$.

\section{CEPHALOMETRY}

Cephalometric measurements were compared between the 10 affected relatives and 10 unaffected relatives matched by priority for sex, family (possible in three cases), and height. The only variables which were different in the affected relatives were the gonion-gnathionhyoid angle (affected $30^{\circ}$ (range 26-34 ${ }^{\circ}$ ), unaffected $21^{\circ}$ (range $\left.19-23^{\circ}\right) ; \mathrm{p}<0.05$ ) and uvular width $(12.7 \mathrm{~mm}$ (range 11.3-14.1 $\mathrm{mm}$ ), $\quad 10.0 \mathrm{~mm}$ (range $9 \cdot 2-10.8 \mathrm{~mm}$ ); $\mathrm{p}<0.01)$.

\section{Discussion}

This study shows that 10 of 40 first degree relatives of non-obese patients with SAHS had more than $15 \mathrm{~A}+\mathrm{H} /$ hour of sleep. No control group was used in this pilot study because apnoeas, hypopnoeas, and desaturations are reproducibly scored by objective criteria, ${ }^{8}$ and abnormal breathing during sleep is rare with a well described frequency in the British population. ${ }^{9}$ The major control comparison for our study is a random sample of 893 middle aged British men ${ }^{9}$ of whom 45 had more than five $4 \%$ desaturations/hour compared with eight of our 40 relatives ( $p<0.0001, \chi^{2}$ test) or seven of our 19 male relatives $(\mathrm{p}<0.0001)$. That study was performed with the same oximeter and a similar desaturation algorithm as was used in our study. The other comparison is with our previous report that none of 33 asymptomatic non-obese $\left(B M I<30 \mathrm{~kg} / \mathrm{m}^{2}\right)$ Edinburgh subjects had more than $15 \mathrm{~A}+\mathrm{H} /$ hour of sleep ${ }^{10}$ while eight of our 35 first order relatives who weighed $<30 \mathrm{~kg} / \mathrm{m}^{2}$ had more than $15 \mathrm{~A}+\mathrm{H} /$ hour of sleep, again indicating that our relatives had abnormal breathing during sleep $(\mathrm{p}<0.005)$.

We do not think our finding of increased irregular breathing and desaturation during sleep in the relatives of non-obese patients with SAHS is affected by the recruitment of only 40 of 62 eligible relatives. In the nine families with $100 \%$ coverage, six of the 19 relatives $(32 \%)$ had $>15 \mathrm{~A}+\mathrm{H} /$ hour of sleep. In addition, the increased rate of snoring among those relatives who did not attend for sleep studies suggests that they would have had an even higher frequency of irregular breathing than those relatives studied, and the fact that they were not studied biased against the positive findings of this study Even if one assumed that all the 22 relatives who declined sleep studies had norma breathing during sleep, our relatives still had an increased frequency of desaturation $(p<0.01)$ and irregular breathing $(p<0.05)$.

Our conclusion is consistent with a simultaneous symptom questionnaire study reporting more daytime sleepiness and apnoeas in relatives of patients with SAHS. ${ }^{11}$ Sleep studies were not performed, however, and families of patients with SAHS might be more aware of these features. Furthermore, the patients with SAHS were obese (mean (SD) BMI 37 (2) $\mathrm{kg} / \mathrm{m}^{2}$ ), although the increased frequency of reported breathing pauses remained when adjustment was attempted for the body mass of the relatives.

Our cephalometric studies have not shown any primary skeletal abnormality in the affected relatives although, as there were only 10 affected relatives, confirmation of this finding is required in a larger number of subjects. The difference in uvular width may reflect either increased fat deposition ${ }^{12}$ or mucosal or muscular changes ${ }^{12}$ which, like the difference in gonion-gnathion-hyoid angle, may be secondary to abnormal breathing during sleep. The inherited abnormality may therefore be altered soft tissue or fat deposition in the neck or a defect of the control of upper airway calibre rather than an inherited skeletal defect.

This pilot study provides sufficient evidence of a familial predisposition to SAHS to warrant further more detailed studies.

This study was supported by the Chest, Heart and Stroke Association (Scotland and UK)

1 Guilleminault C, van der Hoed J, Mitler M. Clinical overview of the sleep apnea syndromes. In: Guilleminault C, Dement W, eds. Sleep apnea syndromes. New York: Alan R Liss, 1978:1-12.

2 Whyte KF, Allen MB, Jeffrey A, Gould GA, Douglas NJ. Clinical features of the sleep apnea/hypopnea syndrome. $Q \mathcal{F}$ Med 1989;72:659-66.

3 Strohl KP, Saunders NA, Feldman NT, Hallett $M$ Obstructive sleep apnoea in family members. $N$ Engl $f$ Med 1978;299:967-73.

4 Elliot J. Obstructive sleep apnea in Georgia family: is it hereditary? $\mathcal{F} A M A$ 1978;240:2611

5 Rechtschaffen A, Kales A, eds. A manual of standardized terminology, techniques and scoring system for sleep stages of human subjects. Bethesda: National Institutes of Health 1968: publication 204 
6 Douglas NJ, Thomas S, Jan MA. Clinical value of polysomnography. Lancet 1992;339:347-50.

7 Yildirim N, Fitzpatrick MF, Wightman AJA, Douglas NJ. The effect of posture on upper airway dimensions in normal subjects and in patients with the sleep apnoeal hypopnea syndrome. Am Rev Respir Dis 1991;144: hypopn

8 Whyte KF, Allen MB, Fitzpatrick MF, Douglas NJ. Accuracy and significance of scoring hypopneas during sleep. Sleep 1992;15:257-60.

9 Stradling JR, Crosby JH. Predictors and prevalence of obstructive sleep apnoea and snoring in 1001 middle aged men. Thorax 1991;46:85-90.

10 Gould GA, Whyte KF, Rhind GB, Airlie MAA, Catteral JR, Shapiro CM, et al. The sleep hypopnea syndrome. Am Rev Respir Dis 1988;137:895-8.

11 Redline S, Tosteson T, Tishler PV, Carskadon MA Milliman RP. Studies in the genetics of obstructive sleep apnea. Familial aggregation of symptoms associated with sleep related breathing disturbances. $\mathrm{Am} \mathrm{Rev}$ Respir Dis 1992;145:440-4.

12 Stauffer JL, Buick MK, Bixler EO, Sharkey FE, Abt AB, Manders EK, et al. Morphology of the uvula in obstructive sleep apnea. Am Rev Respir Dis 1989;140:724-8.

\section{Adventitia}

\section{The assessment of technology: who pays for it?}

New medical technologies, including pharmaceuticals, surgical procedures and therapeutic devices, are some of the factors commonly cited for the explosive rise in the cost of American health care. The use of new technologies accounts for an estimated one third of American health care costs, as much as $\$ 200-300$ billion annually. Yet in the midst of our nearly trillion dollar health care quagmire physicians often operate blindly with regard to what is worthwhile and what is not. This ignorance generates higher costs and forces patients to assume greater risks by accepting unsafe or ineffective treatments, or being denied therapies that ultimately prove safe and effective.

As recent controversies have shown (silicone gel breast implants, Bjork-Shiley heart valves, Halcion, Prozac) the current system of medical technology assessment in America is inadequate for the needs of the exponential growth of cutting edge scientific developments such as gene therapy, fibreoptics, and lasers. Generating sufficient research on new products has become arduous and extremely expensive, and still leaves many questions unanswered before patients are exposed to the products. Health care consumers pay higher prices as companies price their products with an eye toward quickly recouping years of development costs. Moreover, the system's inadequacies cause more American companies to look at the lower costs and greater ease of testing and selling medical devices and drugs in foreign markets. To remain at the forefront of medical technology and to decrease the costs of developing new products, America must overhaul its system of medical technology assessment.

The biomedical industry's aim is to bring products to market expeditiously without prohibitively expensive testing and develop- ment. Yet hospitals and third party payers (including the largest of all third party payers-the Federal Government) want assurances that what they are paying for is safe, effective, and reasonably priced.

What is urgently needed is a less expensive, more efficient system of evaluating the safety, efficacy, benefit, and financial implications of new products. To this purpose, President Clinton should consider a National Health Research Consortium of representative hospitals organised to perform medical research and work with the financial support and cooperation of the pharmaceutical, medical device, and health insurance industries.

Based on the Japanese model of keiretsu where the government supports a particular industry by fostering cooperation between otherwise competing companies, a National Health Care Consortium has obvious advantages. Backed by the combined resources of government and the private sector, the medical community could conduct broader studies on diverse medical, ethical, and financial issues than is currently possible. This benefits undermanned and underfunded government organisations and assists them in the time consuming and labour intensive reevaluation of product studies. Further, a National Consortium could eliminate the costly reduplication of effort currently going on locally in the medical community and within industry.

In line with his plan to improve access and delivery of medical care for all Americans, President Clinton must bring together developers, users, and payers to generate state-ofthe-art research on the appropriate implementation of new drugs, devices, and procedures. Within the scope of his health care reform, Clinton should call for a public/private joint venture National Health Research Consortium. ERIC GLUCK

This column is now open to allcomers (maximum 700 words). We would like to keep this column running. -SGS. 